\title{
Variability of synoptic-scale quasi-stationary thermohaline stratification patterns in the Gulf of Finland in summer 2009
}

\author{
T. Liblik and U. Lips \\ Marine Systems Institute, Tallinn University of Technology, Akadeemia Road 15a, 12618 Tallinn, Estonia \\ Correspondence to: T. Liblik (taavi.liblik@gmail.com)
}

Received: 29 February 2012 - Published in Ocean Sci. Discuss.: 12 March 2012

Revised: 13 July 2012 - Accepted: 22 July 2012 - Published: 13 August 2012

\begin{abstract}
We present and analyze high-resolution observational data of thermohaline structure and currents acquired in the Gulf of Finland (Baltic Sea), using an autonomous buoy profiler and bottom-mounted acoustic Doppler current profiler during July-August 2009. Vertical profiles of temperature and salinity were measured in the upper 50-m layer with a $3 \mathrm{~h}$ time resolution, and vertical profiles of current velocity and direction were recorded with a $10 \mathrm{~min}$ time resolution. Although large temporal variations of vertical temperature and salinity distributions were revealed, it was possible to define several periods with quasi-stationary vertical thermohaline structure. These quasi-stationary stratification patterns persisted for 4-15 days and were dominated by certain physical processes: upwelling, relaxation of upwelling, estuarine circulation and its wind-induced reversal, and downwelling. Vertical profiles of current velocities supported the concept of synoptic-scale, quasi-stationary periods of hydrophysical fields, characterized by distinct layered flow structures and current oscillations. To estimate the contribution of different processes to the changes in stratification, a simple conceptual model was developed. The model accounts for heat flux through the sea surface, wind mixing, wind-induced transport (parallel to the horizontal salinity gradient) in the upper layer, and estuarine circulation. It reproduced observed changes in vertical stratification reasonably well. The largest discrepancies between observations and model results were found when water motions across the Gulf and associated vertical displacements of isopycnals (upwelling or downwelling) were dominant processes.
\end{abstract}

\section{Introduction}

Vertical stratification of the water column in oceans and seas is a key factor shaping the distribution and transport of substances. The Gulf of Finland, a 400-km-long and 48-135$\mathrm{km}$-wide sub-basin of the Baltic Sea, is dominated by fresh water discharge at its eastern end and free water exchange with the Baltic Proper through its western border (Alenius et al., 1998). This creates both horizontal and vertical gradients of salinity. Surface layer salinity on the Practical Salinity Scale varies from 1-3 in the east to 6 in the west; there is also a slight decrease across the Gulf from south to north. In summer, the water column in deeper areas of the Gulf consists of three layers: upper mixed layer (UML), cold intermediate layer (CIL), and the near-bottom layer, which is saltier and slightly warmer than the CIL. These water layers are separated by pycnoclines: the thermocline at 10-20-m depths and the permanent halocline at 60-70-m depths.

Based on analysis of vertical profiles of temperature and salinity collected in the Gulf from 1987-2008, long-term average parameters of vertical thermohaline structure in summer (June-August) have been estimated (Liblik and Lips, 2011). Average UML depth, temperature and salinity were $12.8 \mathrm{~m}, 15.2^{\circ} \mathrm{C}$ and 5.2 , respectively. The base of the thermocline (BT) was situated on average at $27.2 \mathrm{~m}$, and thickness of the thermocline was $14.4 \mathrm{~m}$. Mean temperature of the coldest point of temperature profiles (CIL temperature) and its depth (CIL depth) were $2.5^{\circ} \mathrm{C}$ and $42 \mathrm{~m}$. The center of the halocline, defined as the depth of maximum salinity gradient, was at average depth $67 \mathrm{~m}$. It has been shown that all stratification parameters reveal temporal variations influenced by different factors (Liblik and Lips, 2011). For instance, CIL temperature depended strongly on preceding winter severities and the 
Baltic Sea index in January-February, although it has been shown that denser surface waters sinking from shallow areas during autumn and spring can also influence CIL temperature the following summer (Chubarenko and Demchenko, 2010). Salinity increase in the deep layer observed after the mid1990s was suggested to be mostly caused by a major inflow of North Sea waters into the Baltic Sea in 1993. This interrupted stagnation in Baltic Proper deep layers (Matthäus and Lass, 1995) and further inflows, as observed in 2003 (Feistel et al., 2003).

Mean along-channel circulation in the elongated Gulf of Finland is characterized by outflow in the upper layer and inflow in the deeper layer. The intensity or occasional reversal of this estuarine circulation pattern depends on prevailing winds, which may cause strengthening or weakening of the vertical stratification (Elken et al., 2003; Liblik and Lips, 2011). Simpson et al. (1990) introduced a model to describe vertical stratification in a tidal estuary, by adapting energy considerations used in the surface heating problem to describe competition between the stabilizing effect of fresh water and vertical mixing by tidal and wind stirring. A simulation of the monthly cycle based on this model, including straining, stirring and estuarine circulation, was in qualitative agreement with the principal observed features in Liverpool Bay. Although tidal stirring is not an issue in the Gulf of Finland, predicting the development of stratification is an even more difficult problem. This is because the stratification at a certain point also very much depends on across-Gulf motions of water masses. The latter often leads to pronounced upwelling or downwelling events along the coasts (Lips et al., 2009). In some cases, up to $38 \%$ of the area of the Gulf surface waters is replaced by upwelled waters (Uiboupin and Laanemets, 2009). It has been shown by a modelling study that mesoscale processes are dominant dynamical features of the Gulf, especially in its coastal zone (Laanemets et al., 2011). Thus, mesoscale eddies and fronts with characteristic horizontal scale determined by the internal Rossby radius (Alenius et al., 2003) create corresponding horizontal variability of vertical stratification, as has been documented by repeated across-Gulf surveys (e.g. Lips et al., 2010).

Simulations of vertical stratification using 3-D numerical models are not yet reliable (Myrberg et al., 2010). However, a number of studies have indicated the importance of vertical thermohaline structure to ecosystem components of the gulf, such as phytoplankton species composition (Rantajärvi et al., 1998) and sub-surface maxima of phytoplankton biomass (Lips et al., 2010), cyanobacteria blooms (Lips and Lips, 2008), distribution of pelagic fish (Stepputtis et al., 2011), macrozoobenthos abundance (Laine et al., 2007), and oxygen concentrations in the near-bottom layer (Maximov, 2006). Thermohaline structure and related processes in the Gulf have been mainly studied using classical observations aboard research vessels. Remote sensing methods and FerryBox systems do not reveal vertical structure of the water column. Because of the Gulf's morphology (a narrow and relatively shal- low basin) and high marine traffic intensity, widespread technologies for water column profiling (like ARGO floats) have not been applied there. An autonomous profiling buoy station was first used in the Gulf in summer 2009. An analysis of autonomously collected data, together with phytoplankton sampling and counting results, suggests that phytoplankton dynamics is to a large extent determined by stratification conditions (Lips et al., 2011).

In this study, we present and analyze high-resolution observational data of thermohaline structure and currents in the Gulf. The main aim is to define distinct stratification patterns in the water layer from the sea surface to a depth of 40-50 m, including the seasonal thermocline, and to explain under what conditions these patterns occur.

\section{Data and methods}

\subsection{Observations}

The CTD data analyzed were collected by an autonomous vertical water column profiler (Idronaut s.r.l) mounted on a specially designed surface buoy (Flydog Solutions LCC). The buoy was anchored in the central Gulf of Finland, between Tallinnamadal and Uusmadal shoals at depth $85 \mathrm{~m}$ (Fig. 1).

Vertical temperature and salinity profiles were obtained using an Idronaut s.r.l OS316 CTD probe. Salinity values were calculated using algorithms of Fofonoff and Millard Jr. (1983), and are presented without units on the Practical Salinity Scale of 1978 . The autonomously collected salinity data were compared with data collected by an OS320plus CTD probe (Idronaut s.r.l) aboard the research vessel, and the quality of salinity data was checked against water sample analyses by an Autosal high precision salinometer (Guildline). Altogether, 314 CTD profiles in the water layer from 2 to $50 \mathrm{~m}$ were collected from 30 June through 28 August 2009. Data acquired with vertical resolution about $10 \mathrm{~cm}$ were processed and stored for further analysis as vertical profiles of temperature, salinity and density, at resolution $0.5 \mathrm{~m}$.

CTD profiles were collected with a $3 \mathrm{~h}$ temporal resolution, but because of maintenance and technical problems, some longer breaks occurred. Data on current velocity and direction were collected by an acoustic Doppler current profiler (ADCP; Teledyne RD Instruments). The ADCP was mounted close to the buoy profiler, and was set to separate 36 vertical bins by $2-\mathrm{m}$ steps. The shallowest bin was at the depth range 9-11 $\mathrm{m}$ and the deepest bin at the range 79-81 $\mathrm{m}$.

Wind data from June to August were obtained from the Kalbådagrund meteorological station (Finnish Meteorological Institute) in the central Gulf, and other hydrometeorological data (cloudiness, partial pressure of water vapor, relative humidity, air temperature, solar irradiation) from Harku meteostation in Estonia (Estonian Meteorological and Hydrological Institute).

Information on the datasets used is summarized in Table 1. 


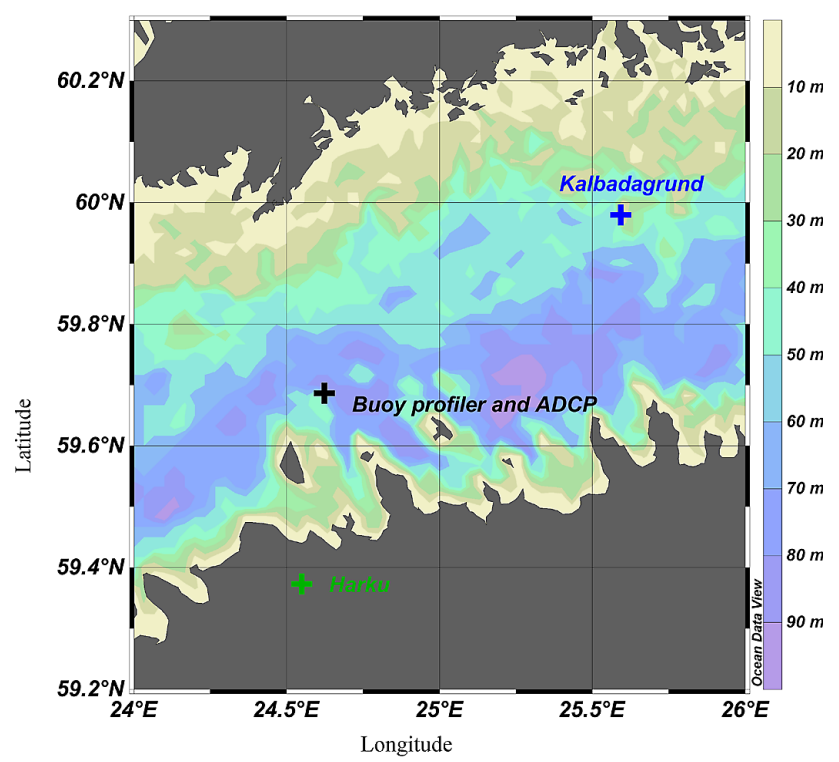

Fig. 1. Locations of buoy profiler and ADCP mooring, and Kalbådagrund and Harku meteorological stations.

\subsection{Definitions}

Vertical thermohaline structure measured by the buoy profiler in the upper 50-m layer was quantitatively described by estimating UML depth, BT, thickness of the thermocline, and depth of the strongest density gradient. The UML depth was defined as the minimum depth where the criterion $\rho_{z}$ $\geq \rho_{4}+0.25 \mathrm{~kg} \mathrm{~m}^{-3}$ was satisfied ( $\rho_{z}$ is density at depth $z$, and $\rho_{4}$ is density at 4-m depth). The BT was defined as the maximum depth where the temperature was $\geq 5^{\circ} \mathrm{C}$. Thermocline thickness was defined as the difference between BT and UML depth, and the depth of the strongest density gradient was defined as the depth of the largest difference between two successive density values, calculated over the 0.5 $m$ depth step.

A number of parameters, such as UML depth, BT depth and depth of a certain isohaline, were tested for use as quantitative criteria for definition of periods with specific quasistationary stratification patterns. Since no parameter was found perfect, periods characterizing dominance of a few distinct processes were selected qualitatively, based on observed variations in the vertical temperature and salinity distributions (Fig. 2) and TS diagrams (Fig. 3). Mean values of parameters for a certain period were estimated as arithmetic averages over all profiles within the period when corresponding wind characteristics were calculated, with a time lag of $15 \mathrm{~h}$ (Elken et al., 2003).

Vertical stratification was described by the potential energy anomaly $P$ (Simpson and Bowers, 1981; Simpson et al., 1990) calculated as
Table 1. Measurement information.

\begin{tabular}{|c|c|c|c|}
\hline \multirow[t]{2}{*}{ Data type } & \multicolumn{2}{|c|}{ Data availability } & \multirow{2}{*}{$\begin{array}{l}\text { Measuring } \\
\text { interval }\end{array}$} \\
\hline & From & To & \\
\hline CTD profiles & 30.06 .2009 & 28.08 .2009 & $3 \mathrm{~h}$ \\
\hline Current profiles & 23.07.2009 & 31.08 .2009 & $10 \mathrm{~min}$ \\
\hline Wind data & 01.06 .2009 & 31.08.2009 & $3 \mathrm{~h}$ \\
\hline Cloudiness & 01.06 .2009 & 31.08.2009 & $3 \mathrm{~h}$ \\
\hline Other meteorological data & 01.06 .2009 & 31.08 .2009 & $1 \mathrm{~h}$ \\
\hline
\end{tabular}

$P=\frac{1}{h} \int_{-h}^{0}\left(\rho_{\mathrm{A}}-\rho\right) g z \mathrm{~d} z, \rho_{\mathrm{A}}=\frac{1}{h} \int_{-h}^{0} \rho \mathrm{d} z$

where $\rho(z)$ is the density profile over the water column of depth $h$. The stratification parameter $P\left(\mathrm{~J} \mathrm{~m}^{-3}\right)$ is the work required to bring about complete mixing of the water column under consideration. The stratification parameter in estuaries has usually been estimated over the entire water column. In the present study, integration was conducted down to depth $40 \mathrm{~m}$, which is close to the long-term mean depth of the CIL (the coldest point of the vertical temperature profile) of $42 \mathrm{~m}$ (Liblik and Lips, 2011), since the aim was to study changes in the stratification pattern at depths of the seasonal thermocline.

\subsection{Model setup}

The temporal development of $P$ was modeled as the sum of the following four terms:

$$
\frac{\mathrm{d} P}{\mathrm{~d} t}=S_{\mathrm{b}}+S_{\mathrm{m}}+S_{\mathrm{a}}+S_{\mathrm{e}}
$$

where the first term on the right-hand side, $S_{\mathrm{b}}$, is the time rate of change of potential energy of the water column due to upper layer heating or cooling. The second term, $S_{\mathrm{m}}$, is the decrease of stratification from wind mixing, and the third term, $S_{\mathrm{a}}$, is a parameter describing the decrease or increase of stratification caused by wind-induced transport in the surface layer. The last term on the right, $S_{\mathrm{e}}$, is a parameter describing the mean estuarine flow that always reinforces the stratification.

The first two terms on the right, $S_{\mathrm{b}}$ and $S_{\mathrm{m}}$, were calculated as suggested by Simpson et al. (1990):

$$
\begin{aligned}
& S_{\mathrm{b}}=\frac{\alpha g Q_{\mathrm{TOT}}}{2 c_{\mathrm{p}}} ; \\
& S_{\mathrm{m}}=-\delta k_{\mathrm{s}} \rho_{\mathrm{a}} \frac{W^{3}}{h} .
\end{aligned}
$$

These terms are dependent on the surface heating/cooling rate $Q_{\text {Tот }}$ (see below) and wind speed $W$, respectively. In the calculations, the depth $h=40 \mathrm{~m}$ was considered and 


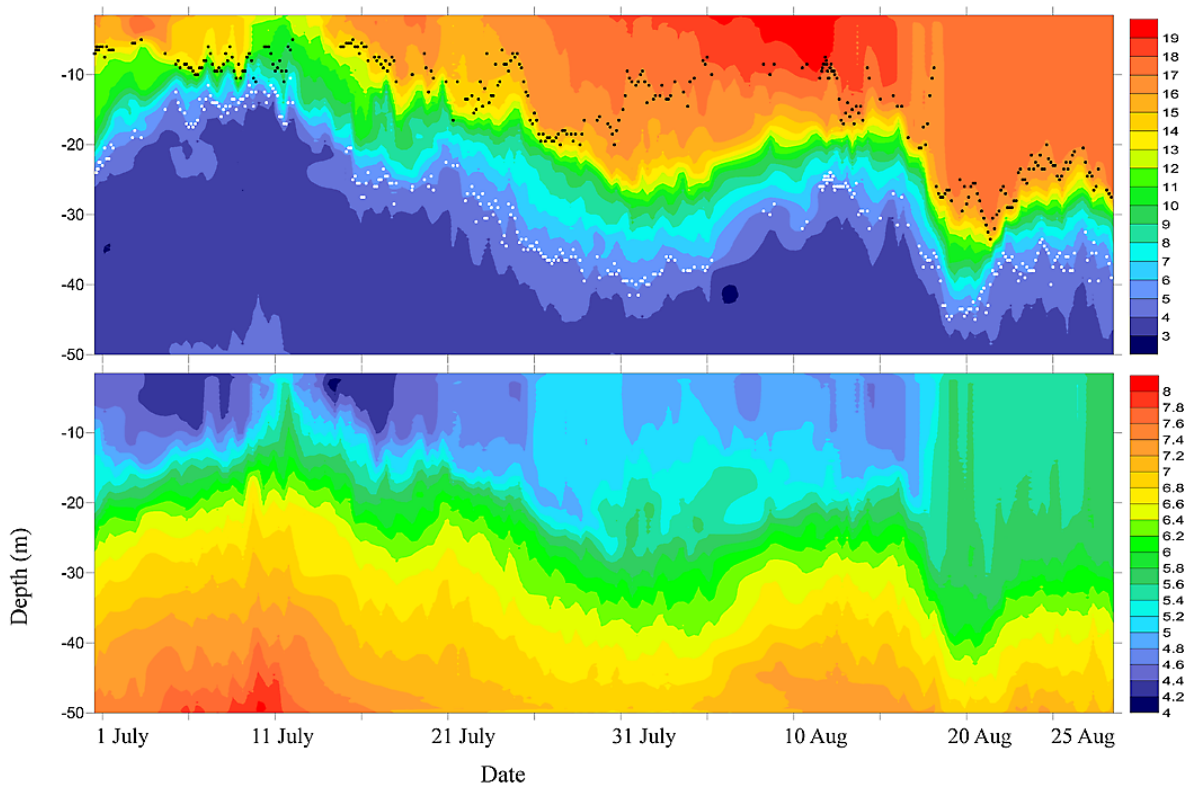

Fig. 2. Temporal variations of vertical distributions of temperature (upper panel) and salinity (lower panel) at the buoy station during summer 2009. Black and white dots in the temperature plot indicate UML and BT depths, respectively.
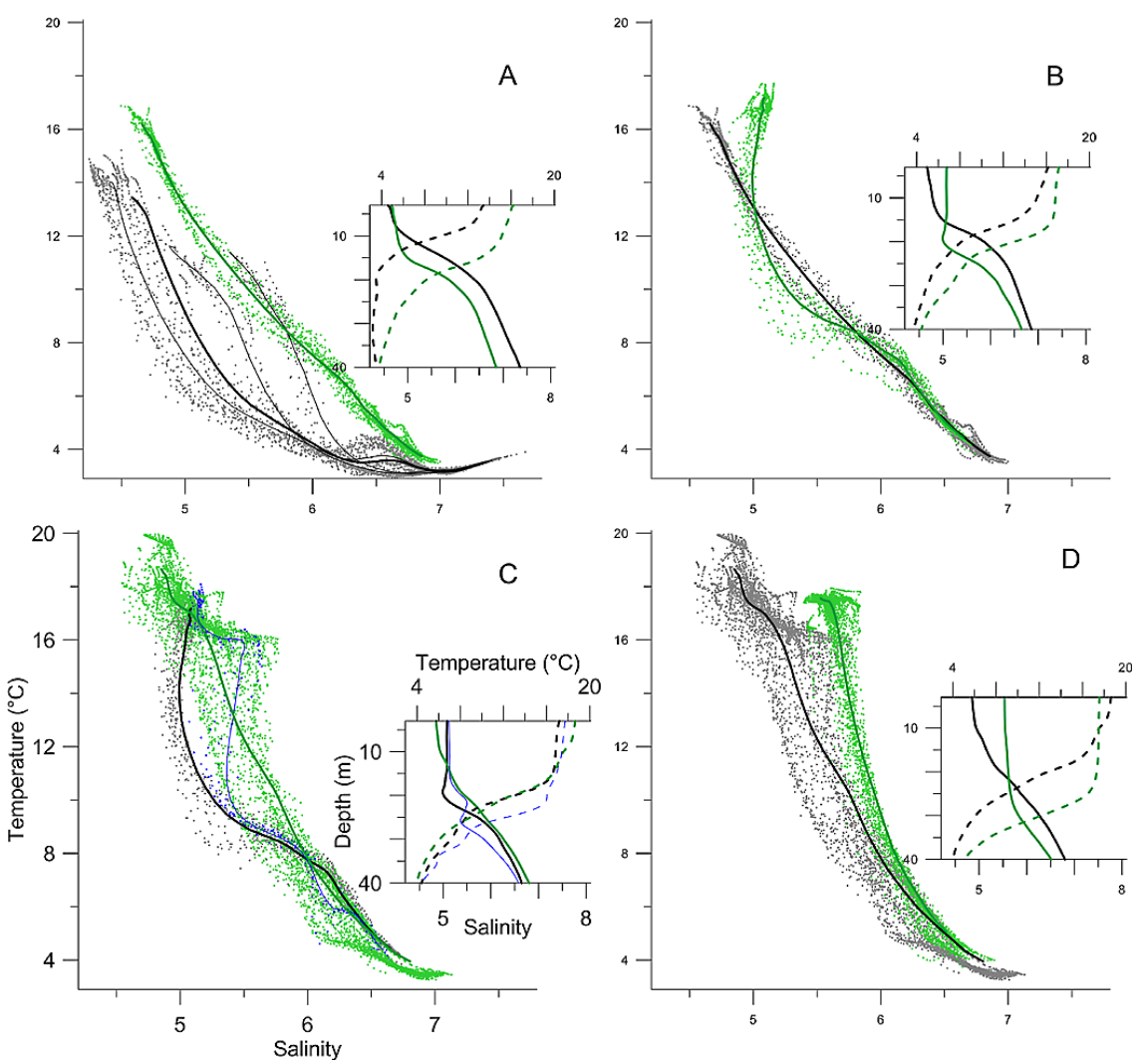

Fig. 3. TS diagrams. Temperature and salinity scatter plots, mean TS curves and mean temperature and salinity profiles for five periods: first and second periods (A), second and third periods (B), third and fourth periods (C), and fourth and fifth periods (D). In panel (A), three phases of first period are indicated by black thin curves; in panel $(\mathbf{C})$ the transition period between third and fourth periods is marked by blue dots and lines. In each plot, black curves and grey dots represent earlier periods and green curves and dots represent later periods. In panels of mean vertical profiles, solid curves represent salinity and dashed curves are temperature. 
the following constants were used: specific heat of seawater $c_{\mathrm{p}}=4000 \mathrm{~J}(\mathrm{kgC})^{-1}$, air density $\rho_{\mathrm{a}}=1.3 \mathrm{~kg} \mathrm{~m}^{-3}$, effective drag coefficient $k_{\mathrm{s}}=10^{-3}$ and efficiency of mixing $\delta=$ $10^{-3}$. Thermal expansion coefficient $\alpha$ was calculated according to McDougall (1987).

The third term $S_{\mathrm{a}}$ was calculated using the equation of Oey et al. (1987), applied by Pavelson et al. (1997) in the Gulf of Finland:

$S_{\mathrm{a}}=\frac{g \rho_{\mathrm{y}} \tau_{x} h}{2 f \rho_{0}}$

where $\rho_{0}$ is the reference density of seawater $\left(1003 \mathrm{~kg} \mathrm{~m}^{-3}\right)$ and $f$ is the Coriolis parameter. $S_{\mathrm{a}}$ depends on wind stress $\tau_{x}$, which can increase seaward flow in the surface layer and thus strengthen stratification, or vice versa. The following assumptions and choices of parameters were made: The most appropriate wind direction for seaward flow intensification was $25^{\circ}$ (Elken et al., 2003; Lips et al., 2008), the alongGulf horizontal density gradient $\rho_{y}=5 \times 10^{-6} \mathrm{~kg} \mathrm{~m}^{-4}$ (Alenius et al., 1998), and UML depth $h$ was $15 \mathrm{~m}$ (Liblik and Lips, 2011).

The fourth term $S_{\mathrm{e}}$ was considered constant over the study period, at $5.5 \times 10^{-5} \mathrm{~J} \mathrm{~m}^{-3} \mathrm{~s}^{-1}$. It corresponds to a permanent outflow at the rate of $2 \mathrm{~cm} \mathrm{~s}^{-1}$ in the upper 15 -m layer.

Since the mean UML temperature does not reveal significant regular changes along the Gulf (Alenius et al., 1998; Liblik, 2012), the advective heat fluxes can be neglected, and total heat flux is represented as follows:

$Q_{\mathrm{TOT}}=Q_{\mathrm{SW}}+Q_{\mathrm{LW}}+Q_{\mathrm{S}}+Q_{\mathrm{L}}$

where $Q_{\mathrm{SW}}$ is short wave radiation, $Q_{\mathrm{LW}}$ is net long-wave radiation, $Q_{\mathrm{S}}$ is sensible heat flux, and $Q_{\mathrm{L}}$ is latent heat flux.

Short-wave radiation was roughly considered as $90 \%$ (constant sea surface albedo of $10 \%$ was assumed) of measured solar irradiation at Harku Meteostation.

Outgoing long-wave radiation was calculated by the Stefan-Boltzmann law and incoming long-wave radiation as in Omstedt (1990), whereby following the input data were used: air temperature, sea surface temperature, cloudiness, and partial pressure of water vapor.

Sensible heat flux was calculated with a bulk formula:

$Q_{\mathrm{S}}=\rho_{\mathrm{a}} c_{\mathrm{pa}} c_{\mathrm{aw}}^{\mathrm{s}} W\left(T_{\mathrm{a}}-T_{\mathrm{w}}\right)$

where $c_{\mathrm{pa}}$ is the specific heat of air $\left(\mathrm{J} \mathrm{kg}^{-1} \mathrm{~K}^{-1}\right), c_{\mathrm{aw}}^{\mathrm{s}}$ is the Stanton number, $T_{\mathrm{a}}$ is air temperature, and $T_{\mathrm{w}}$ is sea surface temperature. Stanton numbers for stable $\left(T_{\mathrm{a}}>T_{\mathrm{w}}\right)$ and unstable $\left(T_{\mathrm{a}}<T_{\mathrm{w}}\right)$ atmospheric boundary layers are 0.66 and 1.13, respectively (Large and Pond, 1982).

Latent heat flux was calculated as follows:

$Q_{\mathrm{L}}=L_{\mathrm{aw}} E$

where $L_{\text {aw }}$ is the specific heat of evaporation and $E$ is evaporation.
Evaporation was calculated from the specific humidity difference at $2 \mathrm{~m}$ height and just above sea level. Specific humidity values were calculated as in Maykut (1986), and input variables such as air temperature, sea surface temperature and relative humidity were used.

\section{Results}

\subsection{Temperature and salinity distribution}

\subsubsection{General description}

The UML depth, its temperature and salinity, and the seasonal thermocline revealed very high variability over the study period (Fig. 2). Overall mean temperature in the surface layer $(3 \mathrm{~m})$ during July-August $2009\left(16.9^{\circ} \mathrm{C}\right)$ was close to the long-term average, while salinity during JulyAugust 2009 (4.9) was lower than the average of 19872008. Mean monthly surface layer temperature and salinity were lower in July $\left(15.7^{\circ} \mathrm{C}\right.$ and 4.7$)$ and higher in August (18.1 ${ }^{\circ} \mathrm{C}$ and 5.2). The mean UML was considerably thinner in July $(10.3 \mathrm{~m})$ than in August $(17.4 \mathrm{~m})$. These estimates were shallower in July and deeper in August relative to average monthly UML depths from 1987-2008 (12.1 m in July and $14.9 \mathrm{~m}$ in August). Similar tendencies were revealed by the mean BT depths. These were slightly shallower in July $(25.1 \mathrm{~m})$ and deeper in August (34.9 m) than the 1987-2008 mean values ( 26.5 and $31.6 \mathrm{~m}$, respectively). Nevertheless, thermocline thicknesses in both months (14.8 and $17.5 \mathrm{~m})$ were similar to the long-term mean values (14.4 and $16.7 \mathrm{~m}$ ).

The strongest density gradient was situated on average at 15-m depth in July and 26-m depth in August. Means of the strongest gradient in the profiles were $0.38 \mathrm{~kg} \mathrm{~m}^{-4}$ in July and $0.39 \mathrm{~kg} \mathrm{~m}^{-4}$ in August.

The average flow pattern in the study period was characterized by motion to the northeast and east in the upper $60 \mathrm{~m}$, and to the northwest below that depth. Average current speed varied from $7.3-12.6 \mathrm{~cm} \mathrm{~s}^{-1}$; it was $>10 \mathrm{~cm} \mathrm{~s}^{-1}$ in the upper layer above $20 \mathrm{~m}$ and in the deep layer below $62 \mathrm{~m}$.

The observed variations in vertical distribution of temperature, salinity and current velocity can be interpreted as the result of influences by different hydrophysical processes. A qualitative description of the processes in response to atmospheric forcing was presented by Lips et al. (2011), and can be summarized as follows. Southeasterly winds, which are favorable for upwelling near the southern coast, caused an upwelling event near that coast during 7-13 July. The upwelling waters reached the buoy station on 10 July, causing a temporal temperature decrease and salinity increase measured by the profiler during 10-12 July (Fig. 2). Westsouthwest winds prevailed in the area from 15 July until the end of July, deepening the thermocline and generating southeastward flow in the 20-m upper layer and northwestward flow below the thermocline. The appearance of more saline 
water in the UML on 26 July was related to this flow structure.

A period of weak winds was observed during the first 10 days of August. The flow structure was characterized by a northward (northwestward) flow in the surface layer, and an eastward flow below the thermocline. Temperature increase in the surface layer and strengthening of stratification occurred in response to the calm weather. Strong wind pulses were observed from 10 August through the end of the measurement period. These first caused strong current oscillations in the whole water column and then, when westerly and northwesterly winds prevailed, an intense downwelling event. This event was detected at the measurement site as sharp deepening of the UML from 17 to 19 August.

Considering this qualitative description of the dynamics of the thermohaline structure, five periods were selected from the entire study period (Table 2), which were related to the following dominant processes: (1) upwelling, (2) relaxation of the upwelling, (3) wind-induced reversal of the estuarine circulation, (4) estuarine circulation, and (5) downwelling.

\subsubsection{Characterization of selected periods}

\section{Upwelling}

In the first period (5-12 July), thermohaline structure was affected by upwelling near the southern coast. This resulted in a thin, cold and saltier UML and shallow BT (Table 2). Mean UML and BT depths and thermocline thickness were $8.4 \mathrm{~m}$, $14.3 \mathrm{~m}$ and $5.9 \mathrm{~m}$, respectively. In temperature and salinity scatter plots for the first period (Fig. 3a), three groups with characteristic TS distribution are visible (TS dots are grouped into three clusters). These groups can be regarded as the three phases in development of the upwelling event, or movement of upwelling waters into the study area. The TS curves indicate a slightly larger salinity increase (at fixed temperature) at thermocline depths than in the upper layer. Because of the upwelling event, sea surface temperature declined during the period. However, the period-average heat flux into the sea, estimated using Eqs. (6)-(8), was positive $\left(131 \mathrm{~W} \mathrm{~m}^{-2}\right)$. Mean temperature in the surface layer was the lowest, and consequently the temperature difference through the thermocline (difference between 3 and $40 \mathrm{~m}$ ) was the smallest $\left(9.9^{\circ} \mathrm{C}\right)$ of the five periods. The density difference, however, was still $3.0 \mathrm{~kg} \mathrm{~m}^{-3}$. The latter was because of high salinity at 40-m depth, which resulted in a very strong salinity difference through the thermocline. The strongest density gradients in the vertical profiles were at relatively shallow depths; the mean was only $10.7 \mathrm{~m}$ in the first period.

\section{Upwelling relaxation}

In the second period, meteorological conditions were characterized by a clearly positive heat flux $\left(109 \mathrm{~W} \mathrm{~m}^{-2}\right)$ and relatively strong winds from the southwest, although there were
Table 2. Mean upper mixed layer depth and mean depth of the base of the thermocline in different periods.

\begin{tabular}{lllrr}
\hline $\begin{array}{l}\text { Period } \\
\text { number }\end{array}$ & Dates & $\begin{array}{l}\text { Dominant } \\
\text { processes }\end{array}$ & $\begin{array}{r}\text { Mean UML } \\
\text { depth (m) }\end{array}$ & $\begin{array}{r}\text { Mean BT } \\
\text { depth (m) }\end{array}$ \\
\hline 1 & $05.07-12.07$ & Upwelling & 8.4 & 14.3 \\
2 & $20.07-25.07$ & Upwelling relaxation & 11.0 & 29.4 \\
3 & $25.07-28.07$ & Estuarine circulation & 18.4 & 36.0 \\
& & reversal & & \\
4 & $31.07-15.08$ & Estuarine circulation & 11.3 & 31.5 \\
5 & $18.08-29.08$ & Downwelling & 25.8 & 38.7 \\
\hline
\end{tabular}

occasional strong wind pulses from the southeast. The southwesterly winds caused relaxation of the upwelling. Shortly thereafter, BT depth began to decline, while UML depth even thinned slightly through the period. The UML depth varied from 6.5 to $16.0 \mathrm{~m}$ and BT from 22.5 to $35.0 \mathrm{~m}$; their mean values were estimated at $11.0 \mathrm{~m}$ and $29.4 \mathrm{~m}$, respectively, and mean thermocline thickness was $18.4 \mathrm{~m}$.

Sea surface temperature varied from 14.7 to $16.8^{\circ} \mathrm{C}$, which was clearly higher than in the first period. Salinity was between 4.6 and 4.8, close to the values in the first period. Since the temperature difference through the thermocline $\left(12.5^{\circ} \mathrm{C}\right)$ was stronger and the salinity difference (2.2) weaker than in the first period, the density difference $\left(3.0 \mathrm{~kg} \mathrm{~m}^{-3}\right)$ was similar to the upwelling period. The second-period TS diagrams (Fig. 3a and b) show that ordinary summer stratification was reestablished in the area. TS curves were mostly straight lines in this period, which might indicate that relaxation of the upwelling strongly contributes to vertical mixing of Gulf of Finland waters (Lips et al., 2009).

\section{Reversed circulation}

Moderate and strong winds, mostly from the south and west, prevailed in the third period. The mean E-W wind component was $5.6 \mathrm{~m} \mathrm{~s}^{-1}$ and $\mathrm{N}-\mathrm{S}$ component $1.9 \mathrm{~m} \mathrm{~s}^{-1}$, and mean speed was $6.7 \mathrm{~m} \mathrm{~s}^{-1}$. The latter is in accord with the observed flow pattern (Fig. 4), i.e. eastward flow in the upper layer and strong outflow from the Gulf in the deep layer. Mean heat flux into the sea was $91 \mathrm{~W} \mathrm{~m}^{-2}$, which led to a corresponding surface layer temperature increase during the period. Surface layer temperature and salinity varied from 16.7 to $17.7^{\circ} \mathrm{C}$ and from 4.9 to 5.2 , respectively. The mean salinity difference through the thermocline dropped to 1.6. A slightly greater temperature difference $\left(12.8^{\circ} \mathrm{C}\right)$ was detected, and the mean density difference $\left(2.6 \mathrm{~kg} \mathrm{~m}^{-3}\right)$ decreased. UML and BT depths were 15-19.5 and 34-39.5 $\mathrm{m}$ and were on average 18.4 and $36 \mathrm{~m}$, respectively. Since the BT was deeper than normal, mean thermocline thickness was as high as $17.6 \mathrm{~m}$.

The TS diagrams and mean vertical profiles (Fig. 3b and c) show that upper-layer salinity increased remarkably, while salinity at thermocline depths decreased 


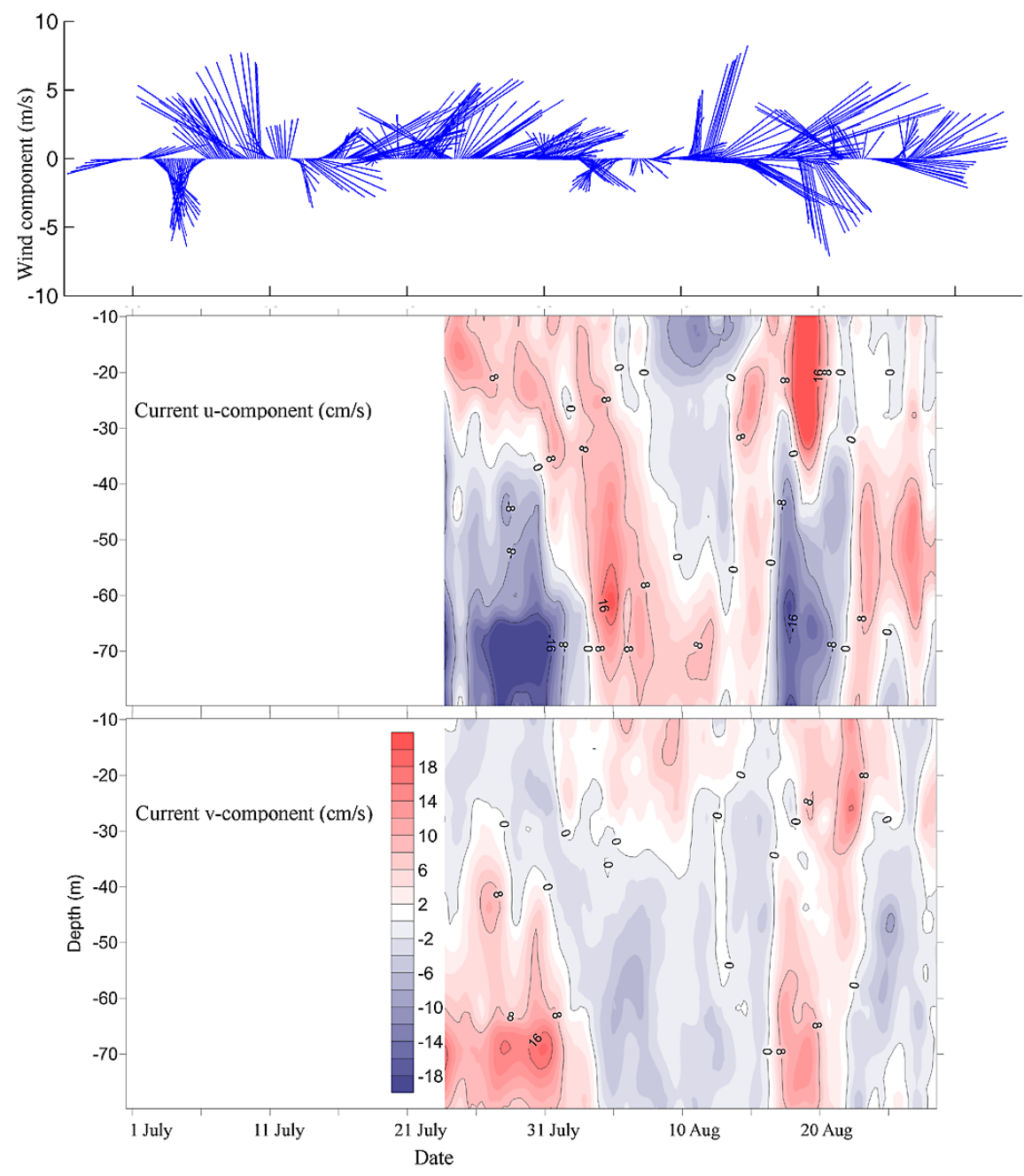

Fig. 4. Wind vectors at Kalbådagrund (top panel), u- and v-component of horizontal current velocity (middle and bottom panel) at buoy station (location in Fig. 1) during summer 2009. Wind vectors and current components were smoothed by running average (24-h window).

relative to the earlier period. These changes correspond to the eastward flow in the upper layer and westward flow in the thermocline and below (Fig. 4). This flow pattern, known as the reversal of the estuarine circulation (Elken et al., 2003; Lips et al., 2008), also likely caused the observed deepening of the thermocline base (Figs. 2 and 3b).

\section{Estuarine circulation}

The fourth period was characterized by weak winds from the north and northeast. On average, the $\mathrm{E}-\mathrm{W}$ wind component was $1.5 \mathrm{~m} \mathrm{~s}^{-1}$, the $\mathrm{N}-\mathrm{S}$ wind component $0.6 \mathrm{~m} \mathrm{~s}^{-1}$, and the mean wind speed $\left(4.8 \mathrm{~m} \mathrm{~s}^{-1}\right)$ was the lowest of the five periods. Mean heat flux was $48 \mathrm{~W} \mathrm{~m}^{-2}$ and the highest daily heat fluxes, up to $128 \mathrm{~W} \mathrm{~m}^{-2}$, were found in this period. Most of the time, currents were directed outward from the Gulf in the upper layer, and into the Gulf in the deeper layer (Fig. 4).
Relatively calm winds and positive heat flux resulted in a shallow UML. Although salinity varied (4.5-5.0) near the overall mean of the study period, sea surface temperature was clearly the highest of the five periods, from 17.4 to $19.9^{\circ} \mathrm{C}$. The UML was as shallow as 7.5-10 $\mathrm{m}$ during most of the period. The BT depth was close to $40 \mathrm{~m}$ during the first days of the period, but gradually moved to shallower locations, up to 25-m depth. As a result, the thermocline, which was initially $>20 \mathrm{~m}$, became $<10 \mathrm{~m}$ at some point during the period. Since the temperature difference $\left(14.7^{\circ} \mathrm{C}\right)$ through the water column was clearly the largest of the five periods, owing to the warm surface layer, the density difference $\left(3.2 \mathrm{~kg} \mathrm{~m}^{-3}\right)$ was also the largest.

Changes in the TS diagram (Fig. 3c and d) can be explained by the influence of estuarine circulation: westward flow in the upper layer and eastward below the thermocline, plus surface warming. The characteristic TS curve was close to a straight line, because of the salinity increase at 
thermocline depths and formation of a fresher and warmer near-surface layer caused by the calm conditions.

\section{Downwelling}

The wind regime in the final period was characterized by strong wind pulses mainly from the west, with mean wind speed $6.5 \mathrm{~m} \mathrm{~s}^{-1}$. Daily mean heat fluxes were close to zero, but on average, heat flux was slightly negative $\left(-19 \mathrm{~W} \mathrm{~m}^{-2}\right)$. The strong winds from the west caused downwelling near the Estonian coast. As a result, mean UML and BT were the deepest of the five periods at 25.8 and $38.7 \mathrm{~m}$, respectively. The maximum density gradient was at an average $30.1-\mathrm{m}$ depth. Owing to changes in wind forcing, there were strong oscillations in current velocity of amplitude $>30 \mathrm{~cm} \mathrm{~s}^{-1}$ in the entire water column. The study period maximum current speed $48 \mathrm{~cm} \mathrm{~s}^{-1}$ was measured at the beginning of this period.

Since corresponding isohalines and isopycnals were forced deeper by downwelling, mean salinity and density difference were the smallest of the five periods at 1.0 and $2.2 \mathrm{~kg} \mathrm{~m}^{-3}$, respectively. The fifth period characteristic TS curve (Fig. 3d) was strongly affected by the downwelling event. Given the eastward transport in the upper layer and vertical mixing (the TS curve was nearly a straight line from the surface to $40 \mathrm{~m}$ ), upper-layer salinity was relatively high and the salinity gradient through the thermocline was relatively weak.

\subsubsection{Shift from reversed to estuarine circulation}

The stratification pattern during the third period was influenced by dominant flow to the east in the upper layer and to the west in the thermocline. This resulted in a characteristic TS curve (Fig. 3b) with slightly fresher waters in the thermocline, beneath saltier water in the upper layer. The water column had a clearly different characteristic TS curve, which was almost a straight line in the TS plot. The shift from the third to fourth period could be defined differently, based on TS characteristics and flow structure. As seen in the TS plot (Fig. 3c), saltier water appeared in the upper part of the thermocline (depth range 20-25 m, marked as "transition period" in Fig. 3c), and slightly fresher water in its deeper part (30$35 \mathrm{~m}$ ). These changes were in accord with the vertical distribution of current vectors: an eastward flow dominated in the upper thermocline, and westward flow in its lower portion. The strongest eastward current was observed in exactly the same depth range as the aforementioned saltier water (20$25 \mathrm{~m})$.

Flow structure (Fig. 5) during the transition period was highly variable in the upper $60-\mathrm{m}$ layer, but strong current was almost permanently directed toward the northwest in the deep layer (below 60-m depth), similar to the third period of reversed circulation. Flow in the upper layer was affected by anticyclonic oscillations, which caused variations of cur- rent speed from 0 to $15 \mathrm{~cm} \mathrm{~s}^{-1}$. Flow at thermocline depths was stronger and more stable in the upper thermocline (upper $25 \mathrm{~m}$ ), but weak and variable in its deeper part (25-40 m). The period of observed oscillations coincided well with the most pronounced spectral peak of current velocity fluctuations over the entire study period $(26 \mathrm{~h})$. A rapid transition of flow structure occurred from 31 July to 1 August: the layered flow was replaced with an eastward current, synchronously oscillating in the entire upper 60-m layer, and westward flow ceased in the deep layer. Later, a typical estuarine circulation scheme was gradually established with westward flow in the upper layer and eastward flow in deeper layers (Fig. 4). Consequently, the TS curve straightened (Fig. 3c), although there were occasional intrusions of saltier waters in the thermocline until 2 August.

\subsection{Comparison between observed and modeled upper layer dynamics}

In this subsection, we present a comparison between measured and modeled changes in stratification. Calculation techniques were described in Sects. 2.2 and 2.3.

The stratification parameter (potential energy anomaly $P$ ) estimated on the basis of vertical density profiles varied during the study period, as would be intuitively expected (Fig. 6). Both upwelling and downwelling decreased stratification. The reversed circulation and estuarine circulation, which dominated during the third and fourth periods, respectively, caused the observed weakening of stratification in the third period and strengthening in the fourth period. The modeled stratification agreed well with measurements during these two periods; a decreased stratification parameter in the middle of the study period, followed by an increase due to upper layer heating and estuarine circulation, are clearly detectable in the modeled stratification time-series.

The largest discrepancies between modeled and measurement-based changes of stratification parameters were during the upwelling event. Although the positive heat flux and easterly winds should increase stratification according to Eqs. (3) and (4), passage of an upwelling front through the measurement site probably caused a rapid decrease of stratification. The other inconsistency is related to the transition between the fourth and fifth periods, for which the observed stratification decrease was much larger than the modeled one. This could be partially related to underestimating stratification strengthening during the fourth period (estuarine circulation) when, according to the measurements, the secondary thermocline was established. However, the weakening of stratification caused by the downwelling was largely not reproduced, since the downward motion of isopycnals (and pycnoclines) due to nearshore convergence of surface waters was not included in the model. 


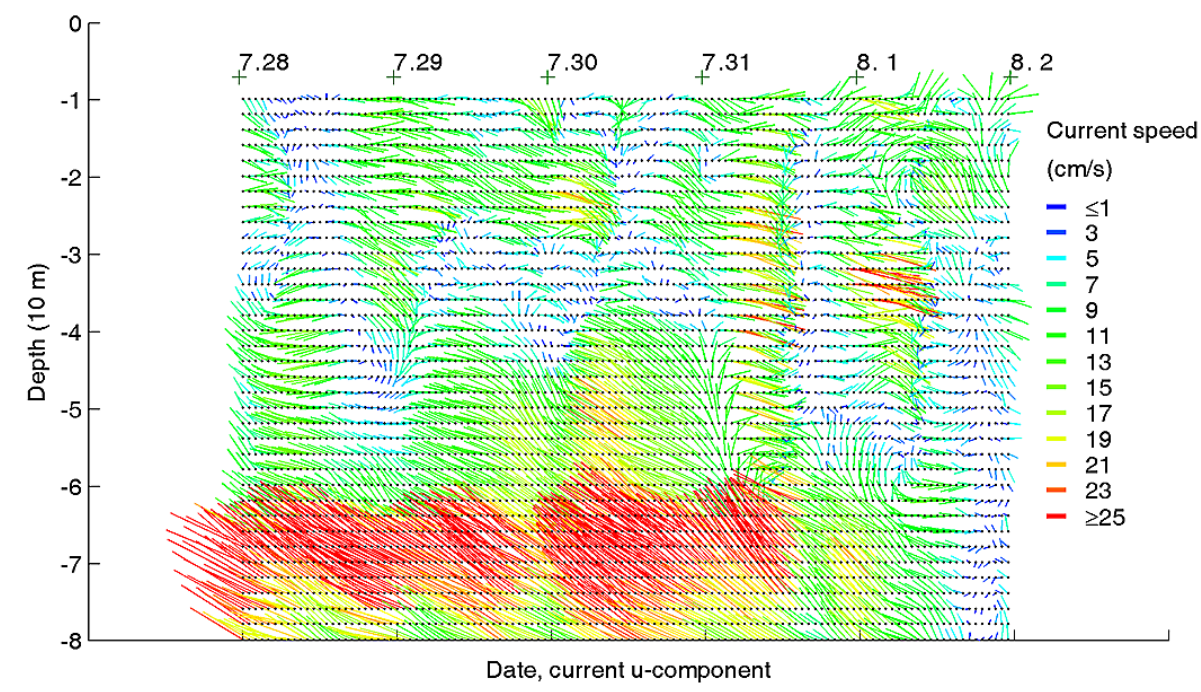

Fig. 5. Vertical distribution of horizontal current vectors from 28 July to 2 August 2009 (location in Fig. 1). Current vectors are averaged over time step $1 \mathrm{~h}$.

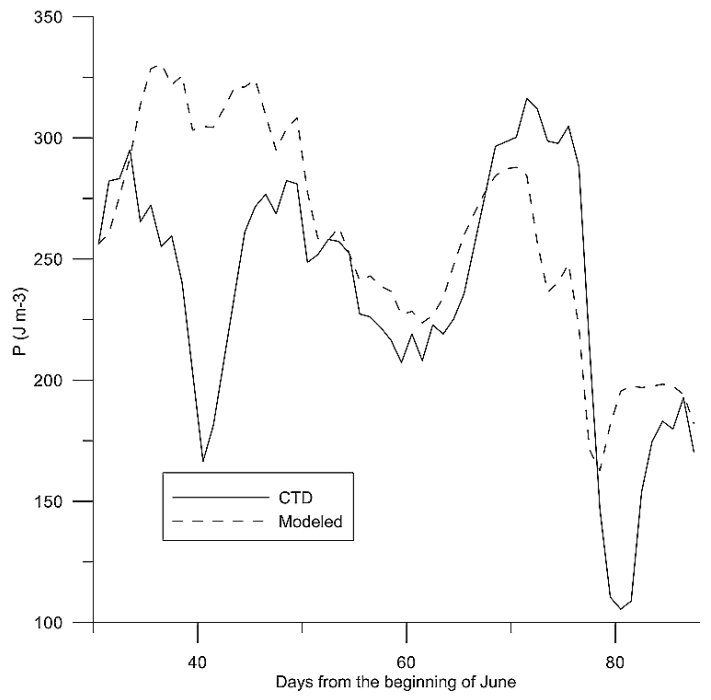

Fig. 6. Development of potential energy anomaly $(P)$. Modeled (using Eq. 2) and CTD data-estimated (using Eq. 1) potential energy anomalies are daily mean values. The first value of modeled stratification parameter was taken equal to the measurement-based first value for synchronizing both time series.

\section{Discussion and conclusions}

High-resolution vertical profiling revealed remarkable variation in vertical distributions of temperature and salinity in the Gulf of Finland between July and August 2009. Based on known synoptic-scale variability of atmospheric forcing, we assumed that variations in vertical thermohaline structure could reveal the variability characterized by certain quasistationary stratification patterns occurring over periods of the same length (several days). We selected five periods with characteristic vertical temperature and salinity distributions and TS curves, and estimated mean parameters of thermohaline structure in each period. Mean temperature and salinity in the upper layer and at UML and BT depths over the entire study period differed only slightly from long-term means (estimated by Liblik and Lips (2011) on the basis of data from 1987-2008). Nevertheless, average parameters for certain selected periods greatly differed from each other and from long-term averages. This shows that prevailing synoptic-scale forcing and related processes significantly alter the vertical stratification, which in turn could produce certain vertical dynamics of the phytoplankton community in this stratified estuary (Lips et al., 2011).

The selected quasi-stationary stratification patterns lasted from 4 to 15 days and were dominated by distinct hydrophysical processes: upwelling, relaxation of the upwelling, reversal of the estuarine circulation, estuarine circulation, and downwelling. Some of these processes occur on the mesoscale and some are related to the estuarine (basin-scale) circulation pattern, which can be reversed according to the prevailing wind forcing (Elken et al., 2003). In the reversed circulation case, thermocline thickness increased and stratification weakened, and there was a clear change of the direction of current through the thermocline. Although the layered flow structure was superimposed by remarkable current oscillations, this observational result supports the suggestion that the winds, which generate along-Gulf flow in the upper layer, cause opposite flow below the thermocline. Subsurface biomass maxima in the vertical distribution of phytoplankton were detected during this period, at the same thermocline depths (Lips et al., 2011) as the observed change in current direction. Similar links between the vertical structure of hydrophysical fields and occurrence of sub-surface 
maxima of phytoplankton biomass have also been observed in other regions (e.g. Velo-Suarez et al., 2010).

Temporal changes of TS curves give indications about the circulation pattern in the Gulf of Finland, bearing in mind existing horizontal gradients of salinity (Lips et al., 2009). If a section of the TS curve is shifted to lower (higher) salinities compared with that recorded at the same location and density range earlier, a movement of waters from east to west (west to east) should have occurred. The observed TS-curve changes demonstrate the sensitivity of stratification and vertical thermohaline structure to prevailing winds. In periods when the estuarine circulation or its reversal were dominant processes, changes in stratification were well simulated by the wind-dependent layered flow along the Gulf, in opposite directions above and below the thermocline (parallel to the average salinity gradient).

Vertical profiles of current velocities support the concept of synoptic-scale, quasi-stationary periods of hydrophysical fields. Strong in- and outflow events, with speeds up to $48 \mathrm{~cm} \mathrm{~s}^{-1}$ from/to the Gulf in both the upper and deeper layer, alternated during periods of dominance of different quasi-stationary stratification patterns. Flow structure at shorter time scales was often affected by oscillations, with the most pronounced spectral peak at $26 \mathrm{~h}$. This is close to $27 \mathrm{~h}$, which is one of the dominant oscillation periods in the Gulf of Finland suggested by Jönsson et al. (2008), and indicated by earlier field studies (e.g. Lilover et al., 2011).

To estimate the contribution of different processes to the stratification changes, a conceptual model was developed following the approach introduced by Simpson (1990). The model accounts for heat flux through the sea surface, wind mixing, wind-induced transport parallel to the horizontal salinity gradient in the upper layer, and estuarine circulation. The model simulated observed changes in vertical stratification reasonably well for periods when surface transport along the Gulf prevailed. The wind-induced transport caused more than half $(60 \%)$ of the modeled variability of the stratification parameter, whereas buoyancy flux due to heating/cooling, wind mixing, and estuarine flow contributed $15 \%, 9 \%$ and $16 \%$, respectively. Cumulative potential energy anomaly changes caused by wind mixing and heating/cooling had similar magnitudes, but worked against each other. The latter phenomenon is typical in the study season, since regional net heat flux in July-August is usually directed into the sea, and wind mixing weakens stratification. Taking that into consideration, the role of wind-induced transport seems even more important as a driving force of Gulf of Finland stratification in summer.

Although the layered flow along the Gulf explained more than half the modeled variability, remarkable discrepancies between modeled and measurement-based changes of potential energy anomaly were evident. The largest mismatches between these modeled and measurement-based changes were during the upwelling event, when the upwelling waters reached the study site (buoy station). However, accord- ing to FerryBox data (Lips et al., 2011), the upwelling front extended a couple of kilometers north of the buoy station. Thus, it might be expected that in the central Gulf, agreement between model and measurements would remain relatively good. Nevertheless, during major upwelling events, like that in August 2006 (Lips et al., 2009), the model will miss the significant decrease in stratification.

Thus, we suggest that, in certain cases, vertical stratification depends strongly on water movement across the Gulf and associated vertical displacement of isopycnals. To advance the simple model presented here, an additional term should be added to Eq. (2). This term must account for the wind-induced drift of surface waters across the Gulf, and resulting convergence or divergence of surface waters and vertical movement of isopycnals. If the wind impulse or cumulative along-Gulf wind stress is strong enough for surfacing of the thermocline (e.g. Haapala, 1994; Uiboupin and Laanemets, 2009), formation and behavior of the upwelling front must also be considered. Since these processes depend on the along-Gulf wind stress, it is reasonable that the largest mismatches between the model and measurements were in the case of easterly winds (Figs. 4 and 6). A series of highresolution CTD sections across the Gulf, such as those in Lips et al. (2009), are needed for parameterization of the influence of upwelling/downwelling on the stratification, as a function of the along-Gulf wind stress and distance from shore.

The movements across the Gulf seem to be the main reason for inconsistency. However, other sources, such as spatial variability of atmospheric forcing, irregular advective heat and salt transport, or parameterization errors might also contribute to the mismatches. For instance, meteorological data for heat flux estimates were obtained from the onshore station, and sea surface temperature was taken from a single site (buoy station). Furthermore, we mostly described the processes at thermocline depths, knowing that in deeper parts of the Gulf, the water column has a three-layer structure and dynamics should be more complicated. However, we showed that, under certain conditions, the simple stratification model is able to simulate the observed changes.

In conclusion, on the basis of high-resolution profiling of the water column during July-August 2009, we distinguished quasi-stationary stratification patterns, which lasted from 4 to 15 days and were dominated by certain hydrophysical processes: upwelling, relaxation of the upwelling, windinduced reversal of the estuarine circulation, estuarine circulation, and downwelling. Vertical profiles of current velocities support the concept of synoptic-scale, quasi-stationary periods of hydrophysical fields. Periods with distinct layered flow structures and current oscillations with prevailing $26 \mathrm{~h}$ periods were revealed. The layered flow structures and sub-mesoscale intrusions of waters with different temperature and salinity along the isopycnals were principal features during the period of reversed estuarine circulation and its transformation back to its ordinary configuration. Our 
simple model, in which heat flux through the sea surface, wind mixing, wind-induced transport (parallel to the horizontal salinity gradient) in the upper layer and estuarine circulation were considered, simulated observed changes in the vertical stratification reasonably well. The largest discrepancies between observations and model results were when water motions across the Gulf and associated vertical displacements of isopycnals (upwelling or downwelling) were dominant processes.

Acknowledgements. The study was financially supported by the Estonian Science Foundation (projects G6955, G9023). We appreciate the help of our colleagues participating in the field measurements. We thank the Finnish Meteorological Institute for wind data from Kalbådagrund, and the Estonian Meteorological and Hydrological Institute for meteorological data from the coastal stations.

Edited by: E. J. M. Delhez

\section{References}

Alenius, P., Myrberg, K., and Nekrasov, A.: The physical oceanography of the Gulf of Finland: a review, Boreal. Env. Res., 3, $97-$ 125, 1998.

Alenius, P., Nekrasov, A., and Myrberg, K.: Variability of the baroclinic Rossby radius in the Gulf of Finland, Cont. Shelf Res., 23, 563-573, 2003

Chubarenko, I. and Demchenko, N.: On contribution of horizontal and intra-layer convection to the formation of the Baltic Sea cold intermediate layer, Ocean Sci., 6, 285-299, doi:10.5194/os6-285-2010, 2010.

Elken, J., Raudsepp, U., and Lips U.: On the estuarine transport reversal in deep layers of the Gulf of Finland, J. Sea Res., 49, 267-274, 2003

Feistel, R., Nausch, G., Matthäus, W., and Hagen, E.: Temporal and Spatial Evolution of the Baltic Deep Water Renewal in spring 2003, Oceanologia, 45, 623-642, 2003.

Fofonoff, N. P. and Millard Jr., R. C.: Algorithms for computation of fundamental properties of seawater, UNESCO Technical Papers in Marine Science, 44, 1-58, 1983.

Haapala, J.: Upwelling and its influence on nutrient concentration in the coastal area of the Hanko Peninsula, entrance of the Gulf of Finland, Estuar. Coast. Shelf Sci., 38, 507-521, 1994.

Jönsson, B. K., Döös, K., Nycander, J., and Lundberg, P.: Standing waves in the Gulf of Finland and their relationship to the basin-wide Baltic seiches, J. Geophys. Res., 113, C03004, doi:10.1029/2006JC003862, 2008.

Laanemets, J., Väli, G., Zhurbas, V., Elken, J., Lips, I., and Lips, U.: Simulation of mesoscale structures and nutrient transport during summer upwelling events in the Gulf of Finland in 2006, Boreal Env. Res., 16A, 15-26, 2011.

Laine A. O., Andersin A.-B., Leiniö S., and Zuur A. F.: Stratification-induced hypoxia as a structuring factor of macrozoobenthos in the open Gulf of Finland (Baltic Sea), J. Sea Res., $57,65-77,2007$.
Large W. G. and Pond, S.: Sensible and latent heat flux measurements over the ocean, J. Phys. Oceanogr., 12, 464-482, 1982.

Liblik, T.: Variability of thermohaline structure in the Gulf of Finland in summer, Ph.D. thesis, Tallinn University of Technology, 159 pp., 2012.

Liblik, T. and Lips, U.: Characteristics and variability of the vertical thermohaline structure in the Gulf of Finland in summer, Boreal Env. Res., 16A, 73-83, 2011.

Lilover, M.-J., Pavelson, J., and Kõuts, T.: Wind forced currents over the shallow Naissaar Bank in the Gulf of Finland, Boreal Env. Res., 16A, 164-174, 2011.

Lips, I. and Lips, U.: Abiotic factors influencing cyanobacterial bloom development in the Gulf of Finland (Baltic Sea), Hydrobiologia, 614, 133-140, 2008.

Lips, U., Lips, I., Liblik, T., and Elken, J.: Estuarine transport versus vertical movement and mixing of water masses in the Gulf of Finland (Baltic Sea), US/EU-Baltic International Symposium, 2008 IEEE/OES, 1-8, doi:10.1109/BALTIC.2008.4625535, 2008.

Lips, I., Lips, U., and Liblik, T.: Consequences of coastal upwelling events on physical and chemical patterns in the central Gulf of Finland (Baltic Sea), Cont. Shelf Res., 29, 1836-1847, 2009.

Lips, U., Lips, I., Liblik, T., and Kuvaldina, N.: Processes responsible for the formation and maintenance of sub-surface chlorophyll maxima in the Gulf of Finland, Estuar. Coast. Shelf. Sci., 88, 339-349, 2010.

Lips, U., Lips, I., Liblik, T., Kikas, V., Altoja, K., Buhhalko, N., and Rünk, N.: Vertical dynamics of summer phytoplankton in a stratified estuary (Gulf of Finland, Baltic Sea), Ocean Dynam., 61, 903-915, 2011.

McDougall, T. J.: Neutral surfaces in the Ocean: Implications for modeling, Geophys. Res. Lett., 14, 797-800, doi:10.1029/GL014i008p00797, 1987.

Matthäus, W. and Lass, H. U.: The recent salt inflow into the Baltic Sea, J. Phys. Oceanogr., 25, 280-286, 1995.

Maximov, A. A.: Causes of the Bottom Hypoxia in the Eastern Part of the Gulf of Finland in the Baltic Sea, Oceanology, 46, 204 210, 2006.

Maykut, G.: The sea surface heat and mass balance, The Geophysics of sea ice, NATO ASI series, Plenum Press, New York and London, 395-464, 1986.

Myrberg, K., Ryabchenko, V., Isaev, A., Vankevich, R., Andrejev, O., Bendtsen, J., Erichsen, A., Funkquist, L., Inkala, A., Neelov, I., Rasmus, K., Medina, M. R., Raudsepp, U., Passenko, J., Söderkvist, J., Sokolov, A., Kuosa, H., Anderson, T. R., Lehmann, A., and Skogen, M. D.: Validation of threedimensional hydrodynamic models of the Gulf of Finland, Boreal Env. Res., 15, 453-479, 2010.

Oey, L. Y., Atkinson, L. P., and Blanton, J. O.: Shoreward intrusion of upper Gulf Stream water onto the U.S. southeastern continental shelf, J. Phys. Oceanogr., 17, 2318-2333, 1987.

Omstedt, A.: A coupled one-dimensional sea ice model applied to a semi-enclosed basin, Tellus, 42A, 568-582, 1990.

Pavelson, J., Laanemets, J., Kononen, K., and Nõmmann, S.: Quasipermanent density front at the entrance to the Gulf of Finland: response to wind forcing, Cont. Shelf Res., 17, 253-265, 1997.

Rantajärvi, E., Gran, V., Hällfors, S., and Olsonen, R.: Effects of environmental factors on the phytoplankton community in the Gulf of Finland - unattended high frequency measurements and multivariate analyses, Hydrobiologia, 363, 127-139, 1998. 
Simpson, J. H. and Bowers, D. G.: Models of stratification and frontal movement in shelf areas, Deep-Sea Res., 28, 727-738, 1981.

Simpson, J. H., Brown, J., Matthews, J., and Allen, G.: Tidal straining, density currents, and stirring in the control of estuarine stratification, Estuaries, 13, 125-132, 1990.

Stepputtis, D., Hinrichsen, H.-H., Bottcher, U., Gotze, E., and Mohrholz, V.: An example of meso-scale hydrographic features in the central Baltic Sea and their influence on the distribution and vertical migration of sprat, Sprattus sprattus balticus (Schn.), Fish. Oceanogr., 20, 82-88, 2011.
Uiboupin, R. and Laanemets, J.: Upwelling characteristics derived from satellite sea surface temperature data in the Gulf of Finland, Baltic Sea, Boreal Env. Res., 14, 297-304, 2009.

Velo-Suarez, L., Fernand, M., Gentien, P., and Reguera, B.: Hydrodynamic conditions associated with the formation, maintenance and dissipation of a phytoplankton thin layer in a coastal upwelling system, Cont. Shelf Res., 30, 193-202, 2010. 